St George's, University of London*

Peter Garrard

St George's, University of London**

\title{
SPOKEN DISCOURSE IN ALZHEIMER'S DISEASE: A REVIEW
}

\section{INTRODUCTION: ALZHEIMER'S DISEASE - TYPICAL AND ATYPICAL}

Alzheimer's disease (AD) is the most common cause of late life cognitive deterioration and dementia. It is a progressive, neurodegenerative disease with a characteristic pathological signature, which shows an early predilection for brain structures (mesial temporal regions and limbic circuit) that are intimately involved in memory. A probable clinical diagnosis of $\mathrm{AD}$ can be made during life on the basis of symptoms and neuropsychological features (McKhann et al. 1984), and an updated set of diagnostic criteria have recently been proposed (Dubois et al. 2007). A definitive diagnosis of $\mathrm{AD}$, on the other hand, requires demonstration of a distinctive pattern of pathological abnormalities in brain tissue (Mirra 1997; Mirra et al. 1991), so a distinction is required between the clinical syndrome of probable $\mathrm{AD}(\mathrm{pAD})$, and the pathological diagnosis of definite $\mathrm{AD}$, which is not usually made until after death. In much of the literature relating to the cognitive profile of $\mathrm{AD}$, this distinction is blurred, but will be repeatedly emphasised in the course of this review.

A series of key publications from the 1980s and 90s (Butters et al. 1987; Christensen et al. 1998; Greene/Hodges 1996; Hodges/Patterson 1995; Kopelman 1985; Welsh et al. 1992) delineated a typical cognitive profile in patients suffering from pAD. All emphasised the profound deficit in episodic memory in the early stages of the condition, showing that these patients suffered from impairments in the encoding and storage of new information, and were insensitive to retrieval cues or structure inherent in the learned material. The impairment has therefore been interpreted as one of new learning, rather than either the accelerated forgetting typical of epilepsy (Blake et al. 2000), or the disrupted retrieval that is seen in some patients with frontal brain lesions (Bondi et al. 1994).

As pAD progresses, additional deficits become apparent in other cognitive abilities. These include: the cognitive process of planning, initiation and regulation of behaviour (executive function); the ability to process visual and spatial information; the ex-

\footnotetext{
* Author's address: Stroke and Dementia Research Centre, St George's, University of London, Cranmer Terrace, London SW17 0RE, UK. Email: sahmed-a@sgul.ac.uk

** Author's address: Stroke and Dementia Research Centre, St George's, University of London, London SW17 0RE, UK. Email: pgarrard@sgul.ac.uk
} 
ecution of complex goal directed movements of the hands (dyspraxia); and languagerelated abilities, dominated by a decline in long term memory of concept knowledge (semantic memory) (Garrard et al. 2005a; Greene et al. 1995; Perry/Hodges 1999; Welsh et al. 1991; Welsh et al. 1992). The accumulation of cognitive deficits is consistent with the increase and spread of the disease burden in the brain, with selective involvement of mesial temporal regions in mildly affected patients, and of more widespread cortical regions in more advanced cases (Braak/Braak 1991).

Deficits in memory and (to a lesser extent) other cognitive abilities can be identified in individuals with mild cognitive impairment (MCI), who do not meet formal criteria for a diagnosis of $\mathrm{pAD}$, but are at an increased risk of developing the syndrome over the ensuing months and years (Petersen et al. 1999; Petersen et al. 2001). If one considers the individual diagnostic criteria for $\mathrm{MCI}$ in parallel with those for $\mathrm{pAD}$, it can be seen that the difference is quantitative, and relates to the threshold at which cognitive difficulty translates into functional impairment and dementia.

The symptoms described above are characteristic of a majority of patients with $\mathrm{pAD}$, but in addition, a number of variant clinical presentations are recognised, due to an atypical distribution of pathology at onset. Some individuals present with predominant and progressive impairments in spatial ability, and show striking atrophy in visual association pathways in the brain (Hof et al. 1997). A frontal variant of $\mathrm{pAD}$ is also recognised, leading to disproportionate impairment in executive functioning (Johnson et al. 1999). Finally, and most relevant to this review, a minority of patients presenting with a slowly progressive language impairment (Alladi et al. 2007; Galton et al. 2000). This third group of patients will be described in greater detail in section 3 .

\section{LANGUAGE PROCESSING IN TYPICAL ALZHEIMER'S DISEASE}

\subsection{Standardised neuropsychological examination}

A number of standardized tests have been used to examine language impairment in pAD. The majority of studies have reached the conclusion that language abnormalities in pAD are dominated by profound anomia, diminished vocabulary, and word finding difficulties, highlighting an early lexico-semantic processing deficit. For example, the widely-used verbal fluency task (in which a patient is given one minute to generate as many words as they can think of beginning with a particular letter, or belonging to a given category) has shown that $\mathrm{pAD}$ patients are consistently more impaired in the latter (semantic) than in the former (phonemic) condition (Garrard et al. 2001; Rosser/Hodges 1994; Salmon et al. 1999). The diagnostic utility of semantic fluency tests is well established (e.g. Monsch et al. 1992; Salmon et al. 1999), and can be used as a marker of disease progression (Perry et al. 2000; Small/Backman 1998).

Impairments in confrontation naming (production of a verbal label when presented with a pictured concept) are also well documented in pAD. Significant differences between patients with early pAD and controls have been demonstrated using instruments such as the Graded Naming Test (GNT) (McKenna/Warrington 1980), which contains 30-items of progressively decreasing lexical frequency and familiarity (Ahmed et al. 
2008; Grundman et al. 2004; Petersen et al. 1999; Thompson et al. 2002). Low frequency/familiarity items prove particularly likely to result in incorrect responses.

In addition to the lexico-semantic impairment in typical $\mathrm{pAD}$, there is mixed evidence for impairment in syntactic abilities. Measures of syntax comprehension include the Token Test (De Renzi/Vignolo 1962) or the Test for the Reception of Grammar (TROG; Bishop 1989). In the Token Test, patients are required to carry out a series of instructions of increasing complexity based on a high frequency vocabulary relating to simple objects such as shapes (e.g. put the red square under the red circle). The TROG entails matching one of four pictures to a series of spoken sentences of progressive grammatical complexity, ranging from simple propositions (e.g. "the boy runs after the dog" to sentences with passive constructions and embedded clauses, such as "the elephant that is being pushed by the boy is large"). A number of studies have revealed little or no effect of syntactic complexity on either comprehension or production (De Jager et al. 2003; Hodges et al. 1996). Lambon Ralph et al. (2003) found that MCI patients performed normally on a battery of language tests, with the single exception of the Token Test. Since patients were unimpaired on the TROG, the authors interpreted the finding as implicating a deficit in the memory and/or attention-related processes that are required to hold sequences of words in short-term ("working") memory (Baddeley et al. 1986), rather than in syntactic processing abilities per se.

Language deterioration in combination with the hallmark memory deficit in MCI has been found to be of increased diagnostic sensitivity and prognostic value. Studying a group of patients with this diagnosis, Ribeiro et al. (2006) reported that around one third were impaired in semantic fluency and a similar proportion on the Token Test. In a separate study, Bozoki et al. (2001) found that patients with impairments in memory coupled with difficulties in one other cognitive domain, including naming and letter fluency tests, carried an eight-fold higher risk of progressing to $\mathrm{pAD}$ after 2 years. De Jager and Budge (2005), also found naming difficulty in MCI to be predictive of later conversion to $\mathrm{pAD}$.

\subsection{Connected speech analysis}

There has been limited work examining connected speech production in $\mathrm{pAD}$. The available data suggest that the impairments discussed above may be more extensive and of earlier onset when employing the more detailed examination of language ability that is provided by this approach. This may be because the production of connected speech is a naturalistic activity, and/or because of the large number of descriptive dimensions that can be obtained from the data. The latter may be especially relevant when considering the impact of neurodegenerative conditions on language ability, as the brain regions involved are widely distributed (Price 2010), while degenerative pathologies are by definition diffuse and (as illustrated) can show considerable neuroanatomical variability.

A further advantage of the study of connected speech is that it can be carried out retrospectively. A number of landmark studies have suggested that language abilities may be vulnerable very early in the disease process. In the narrative samples obtained 
from the Nun study - a longitudinal study of autobiographical data and diary entries collected from convent archives for 678 catholic sisters - Snowdon et al. (1996) showed that, in writings produced as early as the second decade of life, low idea density (number of ideas expressed in a given number of words) was associated with low cognitive performance in later life. Perhaps more remarkably the measure also emerged as a reliable predictor of $\mathrm{AD}$ at post mortem. Garrard et al. (2005b) showed that the last novel of Iris Murdoch, written a year before she was diagnosed with pAD (later confirmed as $\mathrm{AD}$ ) in her mid seventies, contained a more restricted, and higher frequency vocabulary than her earlier works, pointing to a lexico-semantic processing deficit. A later study of a similarly prolific and likewise afflicted Dutch novelist (Gerard Reve) showed that the lexical variety effect was detectable in non-English texts (van Velzen/Garrard 2008). More recently, Garrard put forward the hypothesis that characteristics of the spoken language used by Harold Wilson (a prominent British Prime Minister during the 1960s and 70s) in parliamentary debates shortly before retirement from office, may have been influenced by the early stages of a neurodegenerative illness (anecdotally pAD) that would not emerge until several years later.

Specific deficits have also been observed in tasks based on picture description, such as the Cookie Theft from the Boston Diagnostic Aphasic Examination, (Goodglass/ Kaplan 1983). In this test, the subject is presented with a line drawing depicting a domestic scene: a young boy is standing on a stool reaching for a jar of cookies from a cupboard; the stool is about to topple over; his sister is encouraging the boy to steal the cookie and hand it down to her; the unfolding disaster goes unnoticed by their mother, who is also unaware that the sink at which she is washing dishes is overflowing on to the floor. Participants are simply asked to "describe what is happening in the picture". Samples of open-ended discourse can also be used as samples for analysis.

Hier et al. (1985) reported fewer words and less relevant information, characteristic of reduced lexical diversity in the picture descriptions of patients with pAD. Nicholas et al. (1985) found that pAD patients produced fewer content words and phrases, but significantly more semantic errors, repetitions and empty phrases, and de Lira et al. (2010) reported more lexical errors in the discourse of pAD patients. Ehrlich (1997) found that pAD patients were reduced in the efficiency of their spoken language and required more words to convey target propositions in a narrative task. Similarly, Tomoeda et al. (1996) found that the efficiency and conciseness of picture descriptions provided by patients with pAD compared unfavourably with those of age-matched normal controls.

Analysis of discourse also appears to show syntactic change in pAD. Croisile et al. (1996) found "simplified but relatively correct syntax" in a picture description task provided by patients with $\mathrm{pAD}$ compared to controls, though the effect was more pronounced in written than oral descriptions. Hier et al. (1985) studied oral descriptions obtained from a mixed group, consisting of patients with pAD and dementia due to vascular brain damage. They found all samples to be less complex than those of controls, and the mean clause length to be shorter in the pAD than the vascular group. On the other hand, Kempler et al. (1987) reported an absence of syntactic errors in 
single written sentences produced by patients in the early stages of pAD. Formal analysis of syntactic complexity was not performed, however, and the text samples were necessarily shorter than transcripts of connected speech.

Inconsistencies may be explained by the use of different methods to elicit discourse (conversational speech vs. picture description). The latter affords a number of benefits: the Cookie Theft picture description is a robust, widely used, and simply administered method for eliciting discourse. It allows composite examination of information content, and affords the ability to examine differences between different themes (e.g. persons vs. actions vs. objects). Description draws on a constrained subset of nouns and verbs that are highly frequent and familiar and, for the most part, acquired early in life (Hirsch/Ellis 1994).

\section{ATYPICAL VARIANTS OF ALZHEIMER'S DISEASE}

So far, we have considered the types of language impairment that are evident in patients with typical onset $\mathrm{pAD}$. The atypical presentations with salient language impairments, will now be discussed. These patients present with a pattern of deficits that overlaps with those seen in primary progressive aphasia (PPA).

\subsection{Primary progressive aphasia (PPA)}

PPA is an umbrella term that encompasses a group of neurodegenerative syndromes in which cognitive decline is restricted to one or more components of the language system (Gorno-Tempini et al. 2011; Mesulam 1982). Recently proposed consensus criteria have identified clinical, neuropsychological, and imaging characteristics that describe three distinct subtypes: semantic dementia (SD) is characterized by fluent but empty speech, impaired single-word comprehension, and a high incidence of regularisation errors when reading aloud single words. This constellation of impairments has been convincingly argued to represent disintegration of the stored representation of concept knowledge (semantic memory). SD is associated with selective atrophy in one or both anterior temporal regions, providing a unique opportunity to gain insights in the way such information is stored and organised in the brain (Hodges/Patterson 2007). Progressive non-fluent aphasia (PNFA) is the term used to describe patients with phonologically and/or grammatically distorted speech output, and impaired comprehension at the single word (but not grammatical) level. Atrophy is focused on left inferior frontal and insular regions. The third variant, logopenic aphasia (LPA) is a more recent addition to the PPA syndromes, and will be discussed in some detail in the next section.

PPA is considered to be a distinct clinical syndrome, in which the presenting aphasic difficulties suggest a high likelihood of an underlying degenerative process other than $\mathrm{AD}$. The most frequent pathological associations have been found to be with the group of diseases considered under the heading of frontotemporal lobar degeneration (Grossman 2010). There is, however, growing evidence that variants of AD with early and dominant language impairment are much more common than previously recognized 
(Alladi et al. 2007; Galton et al. 2000; Knibb et al. 2006). Retrospective studies of pathologically confirmed $\mathrm{AD}$, in which progressive aphasia was the predominant feature, have shown both SD and PNFA to be possible presenting syndromes of the condition.

In a detailed comparison of typical and atypical syndromes in pathologically proven $\mathrm{AD}$, Galton et al. (2000) retrospectively examined the clinical presentations of six patients who had presented with PPA. Neuropsychological assessment showed that two cases were classified as PNFA and three others with SD, and one with a mixed aphasic pattern, containing elements of both syndromes. In another recent study, Alladi et al. (2007) found that $\mathrm{AD}$ was the primary pathological diagnosis in almost half of patients present with PNFA, and in three quarters of those with a mixed aphasic syndrome. In contrast, $\mathrm{SD}$ was associated with $\mathrm{AD}$ pathology in only one in ten cases.

\subsection{Logopenic aphasia (LPA)}

Although it should by now be evident that $\mathrm{AD}$ can present with a range of progressive aphasic features, and that progressive aphasia can be produced by more than one degenerative disease, recent descriptions have emphasized a clinically homogenous group of patients with a focal cortical syndrome that appears to be exclusively associated with $\mathrm{AD}$ pathology. LPA has been described as a third variant of PPA, following the first description by Gorno-Tempini et al. (2004). Recent clinico-pathological studies have found that $\mathrm{AD}$ is the most common underlying pathological process in LPA (Mesulam et al. 2008). Retrospective analysis may, of course, show that a diagnosis of LPA may apply to some of the patients described in earlier clinic-pathological studies as presenting with "mixed aphasia", but this hypothesis awaits formal examination.

Detailed clinical, neuropsychological, and imaging studies have allowed the phenotype of LPA to be further refined. The language of patients with this syndrome is characterized by slow production, simplified grammar, word-finding difficulties, and impaired picture naming, with relatively preserved semantics, and particular difficulty with sentence repetition (Gorno-Tempini et al. 2008; Gorno-Tempini et al. 2004; Gorno-Tempini et al. 2011). Patients make phonologic errors in speech but there is no evidence of agrammatism. These observations have been interpreted as representing impairment in auditory verbal short term memory, which has been proposed as a central mechanism in LPA (Gorno-Tempini et al. 2004). In addition to impaired language, neuropsychological profiling in LPA has identified impairments on tests of memory (Mesulam et al. 2008), calculation (Amici et al. 2006; Gorno-Tempini et al. 2004; Rohrer et al. 2010), and limb apraxia (Rohrer et al. 2010).

Imaging studies have identified damage typically in the left temporoparietal junction, and a recent study showed that the severity of imaging abnormalities in this region correlated with the performance on naming and sentence repetition (Leyton et al. 2012). Less consistent damage has been noted in the medial temporal and parietal cortex, posterior cingulate, inferior frontal and temporo-parietal cortex (GornoTempini et al. 2008; Gorno-Tempini et al. 2004; Rohrer et al. 2010). The latter finding is typical of $\mathrm{pAD}$ with language dysfunction at presentation, and in particular of early onset AD (Migliaccio et al. 2009). 


\section{RECENT FINDINGS}

The literature reviewed so far has suggested that, although language deficits in clinically typical pAD may not be present to the same extent as those observed in PPA, they may nonetheless be of clinical importance. A recent series of investigations has therefore been carried out with the aim of characterising connected speech in patients at different stages of clinically typical $\mathrm{pAD}$, all of whom went on to have $\mathrm{AD}$ definitively diagnosed at post-mortem.

Discourse samples, elicited using the Cookie Theft task, had been generated by participants in a longitudinal study of ageing: the Oxford Project to Investigate Memory and Ageing (OPTIMA). This cohort consists of community dwelling elderly persons who were recruited to the study as normal controls or with varying degrees of cognitive impairment. All participants have undergone regular physical, laboratory and cognitive assessment at six to twelve month intervals, during which the evolution of pre-existing cognitive problems has been documented, and the new onset of cognitive impairment in previously asymptomatic individuals observed. All patients selected for language analysis had been recruited either as controls or with a diagnosis of MCI, ensuring that follow-up assessments included the first episode at which subjects with $\mathrm{AD}$ met criteria for clinically probable disease, ensuring homogeneity of disease stage in the sample. Pathological confirmation of control or AD status was obtained at post mortem in all cases.

\subsection{Lexico-semantic processing in early Alzheimer's Disease}

We began by asking whether the previously noted deficit in lexico-semantic processing (cf. section 2) could be observed at the first point of clinical diagnosis of a typical pAD syndrome that was later confirmed at post mortem to have been due to AD. Hereinafter this group will be referred to as early AD (Ahmed et al. in press). Our initial aim was to quantify the semantic content of discourse produced by patients through the analysis of semantic units, defined as "a relevant, truthful and non-redundant fact or plausible inference about the stimulus picture" (Bayles et al. 1989). Production of semantic units can be quantified using a checklist of key elements represented in the picture description task, an approach that has consistently revealed differences between samples of connected speech produced by pAD patients and controls (Croisile et al. 1996; Hier et al. 1985; Tomoeda/Bayles 1993; Vuorinen et al. 2000). Secondly, we aimed to establish whether semantic units were reduced globally, or whether there was a disproportionate reduction of specific classes of information.

Discourse samples were available from 18 early AD patients and 18 matched controls. Following the classification of Croisile et al. (1996) semantic unit identification was scored overall and for four subclasses of information from the picture description task: subjects, locations, objects (noun units) and actions (verb units). Idea density and efficiency of language were also calculated. Early AD transcripts showed significantly reduced units overall, particularly with reference to the persons (mother, boy, girl) and actions (drying dishes, looking out of the window, stealing cookies, falling off stool) in the picture. By contrast, there were no significant differences in the total 
number of words produced or the number of words per minute, suggesting that the early stages of AD are associated with normal fluency of speech. Efficiency was also significantly reduced, whereas conciseness remained within the control range.

Statistical analyses confirmed that these measures (i. e. total units, actions, subjects and efficiency) were highly predictive of diagnosis. Moreover, in a head-to-head comparison between the semantic units produced using nouns and verbs, only the latter remained predictive of group membership. This finding may have some relevance to neurolinguistic studies suggesting that verb retrieval is more severely impaired in agrammatic aphasia, and retrieval of nouns in anomic aphasics (McCarthy/Warrington 1985), as syntactic impairment leads to difficulties in correctly inflecting verbs and using them in appropriate contexts (Friedmann 2000). It should be pointed out, however, that the direction of the association between grammatical category and grammatical abilities is by no means consistent (Berndt et al. 1997).

\subsection{Profiles of connected speech in early Alzheimer's Disease: a comprehensive examination}

The results of our initial study confirmed the characteristic lexico-semantic deficit in early $\mathrm{AD}$, and raised the possibility of a co-existent reduction in the syntactic complexity of the samples. A comprehensive examination of linguistic indices to provide a profile, or profiles of impairment in $\mathrm{AD}$, and investigate how these compare to other language disorders was, however, lacking in the literature. The question was given added importance by the association between LPA and the presence of AD pathology (cf. section 3.2). We therefore set out to investigate whether typical AD patients share the same profile of impairment as those presenting with LPA.

To do so, we utilised a detailed language analysis protocol taken from the quantitative production analysis (QPA) approach (Berndt et al. 2000; Saffran et al. 1989). This is a widely used and comprehensive approach for the analysis of normal and abnormal discourse, whose sensitivity and discriminatory value was recently demonstrated in the context of the clinical variants of PPA (Wilson et al. 2010). QPA yields a combination of indices that are sensitive to five dimensions in connected discourse: speech production, lexical content, fluency, semantic content and syntactic complexity. Owing to the limitations of the rating scale when using small language samples, however, we excluded the semantic indices from the schedule used in our early AD group (cf. Ahmed et al. 2012 for full details).

Individual linguistic variables were reviewed in the same set of Cookie Theft descriptions, produced by the 18 early AD patients and 18 controls (as were considered in the semantic units study) and compared to profiles obtained in the three variants of PPA published by Wilson et al. (2010). The results showed that a third of the early AD group $(n=6)$ produced language with a similar profile to that of controls, suggesting that features of aphasia are not a universal finding in the early stages of typical AD. Linguistic abnormalities were detected in the remainder of the samples, confirming the findings of an earlier study of the prevalence of language deficits at the early stages of the disease (Price et al. 1993). The abnormal samples showed a variety of patterns 
of linguistic impairment, and contained features of all three variants of PPA to varying degrees, with no single homogeneous profile emerging. More specifically, nine patients showed a reduction in one or more measure of syntactic complexity, indexed by a reduction in the proportion of words in sentential contexts, and increased numbers of syntactic errors, coupled with a reduction in the proportion of nouns with determiners and verbs with inflections. Three patients deviated from this majority profile: isolated fluency impairment was noted in two patients, while one patient showed a profile compatible with LPA, with a combination of reduced speech rate, fluency errors, reduced lexical content and syntactic simplification, similar to the profile observed by Wilson and colleagues (2010).

The results suggest that connected speech in clinically typical, early AD conforms to a range of recognised profiles and shares some features with the syndromes of PPA, but that an isolated reduction of syntactic complexity may be specific to the disease. LPA, despite its robust association with AD pathology, was far from ubiquitous, and should therefore continue to be regarded as an atypical presentation of $\mathrm{AD}$, rather than a common clinical feature of clinically typical disease. The occurrence of these distinct language profiles in early AD clearly needs to be replicated in a larger sample of well characterised $\mathrm{pAD}$ patients, but suggests that, with further refinement, connected speech analysis has potential as a diagnostic marker in typical variants of the disease.

\subsection{Connected speech in MCI}

Cognitive and neuropathological changes of $\mathrm{AD}$ can be detected in patients with $\mathrm{MCI}$, and $\mathrm{AD}$ is considered to be particularly likely when a memory deficit can be objectively demonstrated (Petersen et al. 1999; Winblad et al. 2004). A group of researchers at the Mayo Alzheimer's Disease Research Centre followed 220 individuals meeting criteria for $\mathrm{MCI}$ for up to 6 years, and documented $12 \%$ as progressing to dementia in each year of follow-up (around $80 \%$ of the total cohort by the end of the study). In contrast, the incident rate of dementia diagnoses in the same population is only $1-2 \%$ per year. These sobering statistics underline the importance of identifying other cognitive markers of progression, and we therefore asked whether the features characterising language impairment observed at early $\mathrm{AD}$ had also been present when the patients in our sample had met criteria for MCI.

Data from $9 \mathrm{AD}$ patients and 10 matched subjects from the control group were examined. Language analysis combined the semantic processing indices with an abbreviated version of QPA. Group comparisons showed that there were no significant differences between MCI and controls, but closer inspection of the data revealed a difference between MCI and control samples in semantic content. Similarly, MCI patients scored on average one standard deviation below controls on syntactic complexity measures (here assessed according to mean length of utterance, proportion of words in sentences, number of embedded clauses, syntactic errors, nouns preceded by determiners, and verbs with inflections). Both contrasts, however, remained below the threshold (corrected for multiple comparisons) for statistical significance. 
It is likely that the mild difference between controls and MCI patients reported in this small group may achieve greater significance in a larger cohort of patients. Nevertheless, the results suggest that the profile of impairment in MCI mirrors that seen in early $\mathrm{AD}$, suggesting that this same pattern of language impairment progresses from very early in the disease process. Given these findings, further work is warranted in order to firstly replicate these results, and secondly to consolidate suggestions for key features of language that should be used to identify impairment in prodromal $\mathrm{pAD}$, and finally to track these impairments through the course of the disease.

\section{CONCLUDING REMARKS}

The results of recent analyses exploring language impairment in autopsy confirmed cases of AD using a simple, reproducible and ecologically valid approach to data collection (i. e. connected speech sampling), support the existing literature in showing selective impairment of key processes, both at and prior to formal diagnosis. The language deficit in $\mathrm{AD}$ initially disturbs lexico-semantic processing and syntactic complexity of language, and similar changes can be detected at the MCI stage of disease.

Although it is not proposed that language examination should replace memory testing in the diagnosis of $\mathrm{pAD}$, the results nonetheless have clear clinical implications. Profiles of language impairment provide information that can help to distinguish $\mathrm{AD}$ from PPA, and to predict conversion to $\mathrm{pAD}$ in patients with MCI. Further clarification of the profile and nature of these impairments will contribute to the vital goal of determining sensitive and specific markers to aid in providing accurate diagnostic as well as prognostic information for the benefit of the patients and to commence intervention strategies, through pharmacological treatment, psychological intervention, financial planning and other methods, as soon as possible.

\section{References}

Ahmed, Samrah/Robert Arnold/Sian A. Thompson/Kim S. Graham/John R. HoDGes (2008) "Naming of objects, faces and buildings in mild cognitive impairment." Cortex 44, 746-752.

Ahmed, Samrah/Celeste A. De Jager/Anne-Marie Haigh/Peter GarRard (2012) "Logopenic aphasia in Alzheimer's disease: clinical variant or clinical feature?" $J$ Neurol Neurosurg Psychiatry 83, 1056-1062.

Ahmed, Samrah/Celeste A. De JAGer/Anne-Marie Haigh/Peter GarRard (in press) "Semantic processing in connected speech at a uniformly early stage of autopsy confirmed Alzheimer's disease." Neuropsychology.

Alladi, Suvarna/John Xuereb/Thomas BAK/Peter Nestor/Jonathan KNIBB/Karalyn PATtERson et al. (2007) "Focal cortical presentations of Alzheimer's disease." Brain 130, 2636-2645.

Amici, Serena/Maria Luisa Gorno-Tempins/Jennifer M. Ogar/Nina F. Dronkers/Bruce L. Miller (2006) "An overview on Primary Progressive Aphasia and its variants." Behav Neurol 17, 77-87. 
Baddeley, Alan/Robert Logie/S Bressi/Sergio Della Sala/Hans Spinnler (1986)

"Dementia and working memory." Q J Exp Psychol A 38, 603-618.

BaYLEs, Kathryn A./Daniel R. Boone/Cheryl K. TomoedA/Thomas J. Slauson/Alfred W. KASZNIAK (1989) "Differentiating Alzheimer's patients from the normal elderly and stroke patients with aphasia." J Speech Hear Disord 54, 74-87.

Berndt, Rita Sloan/Charlotte C. Mitchum/Anne N. HaEndings/Jennifer SANDSON (1997) "Verb retrieval in aphasia. 1. Characterizing single word impairments." Brain Lang 56, 68-106.

BERndT, Rita Sloan/Sarah WAYLAND/Elizabeth Rochon/Eleanor M. SAFFRAN/Myrna F. SCHWARTZ (2000) Quantitative production analysis: A training manual for the analysis of aphasic sentence production. Hove, U.K.: Psychology Press.

Bishop, Dorothy V. M. (1989) Test for the Reception of Grammar. London: Medical Research Council.

Blake, R V/Stephen J. Wroe/Kristin E. Breen/Rosaleen A. Mccarthy (2000) "Accelerated forgetting in patients with epilepsy: evidence for an impairment in memory consolidation." Brain 123/3, 472-483.

Bondi, Mark W./Andreas U. Monsch/Douglas Galasko/Nelson Butters (1994) "Preclinical cognitive markers of dementia of the Alzheimer type." Neuropsychology 8, 374-384.

Bozoki, Andrea/Bruno Giordani/Judith L. HeIdebrink/Stanley Berent/Norman L. Foster (2001) "Mild cognitive impairments predict dementia in nondemented elderly patients with memory loss." Arch Neurol 58, 411-416.

BrAAK, Heiko/Eva BrAAK (1991) "Neuropathological stageing of Alzheimer-related changes." Acta Neuropathol 82, 239-259.

Butters, Nelson/Eric Granholm/David P. Salmon/Igor Granbt/Jessica Wolfe (1987) "Episodic and semantic memory: a comparison of amnesic and demented patients." J Clin Exp Neuropsychol 9, 479-497.

Christensen, Helen/Michael D. Kopelman/Nicola Stanhope/L Lorentz/P Owen (1998) "Rates of forgetting in Alzheimer dementia." Neuropsychologia 36, 547-557.

Croisile, Bernard/Bernadette Ska/Marie-Josee Brabant/Annik Duchene/Yves LePAGE/Gilbert AIMARD et al. (1996) "Comparative study of oral and written picture description in patients with Alzheimer's disease." Brain Lang 53, 1-19.

DE JAGER, Celeste A./Marc M. Budge (2005) "Stability and predictability of the classification of mild cognitive impairment as assessed by episodic memory test performance over time." Neurocase 11, 72-79.

De JaGer, Celeste A./Eef Hogervorst/Mark Combrinck/Mark M. Budge (2003) "Sensitivity and specificity of neuropsychological tests for mild cognitive impairment, vascular cognitive impairment and Alzheimer's disease." Psychol Med 33, 1039-1050.

De Lira, Juliana Onofre/Karin Zazo Ortiz/Aline Carvalho CAMPANHA/Paulo Hernique BerTolUCCI/Thaís Soares MinetT (2010) "Microlinguistic aspects of the oral narrative in patients with Alzheimer's disease." Int Psychogeriatr 23, 404-412. 
De Renzi, Ennio/Luigi A. Vignolo (1962) "The token test: A sensitive test to detect receptive disturbances in aphasics." Brain 85, 665-678.

Dubois, Bruno/Howard H. Feldman/Claudia Jacova/Steven T. Dekosky/Pascale BARBERGER-GATEAU/Jeffrey Cummings et al. (2007) "Research criteria for the diagnosis of Alzheimer's disease: revising the NINCDS-ADRDA criteria." Lancet Neurol 6, 734-746.

EHrLICH, Jonathan S./Loraine K. OBLER/Lynne ClARK (1997) "Ideational and semantic contributions to narrative production in adults with dementia of the Alzheimer's type." J Commun Disord 30, 79-99.

FriedMANN, Na'ama (2000) "Moving verbs in agrammatic production." In: R. Bastiaanse/Y. Grodzinsky (eds), Grammatical Disorders in Aphasia: A Neurolinguistic Persepective. London: Whurr, 152-170.

Galton, Clare J./Karalyn Patterson/John H. Xuereb/John R. Hodges (2000) "Atypical and typical presentations of Alzheimer's disease: a clinical, neuropsychological, neuroimaging and pathological study of 13 cases." Brain 123/3, 484-498.

GARRARD, Peter (2009) "Cognitive Archaeology: Uses, methods and results." Journal of Neurolinguistics 22, 250-265.

Garrard, Peter/Matthew A. Ralph Lambon/Karalyn Patterson/Katherine H PratT/John R. Hodges (2005a) "Semantic feature knowledge and picture naming in dementia of Alzheimer's type: a new approach." Brain Lang 93, 79-94.

Garrard, Peter/Matthew A. RalPh Lambon/Peter C. Watson/Jane Powis/Karalyn PATterson/John R. Hodges (2001) "Longitudinal profiles of semantic impairment for living and nonliving concepts in dementia of Alzheimer's type." J Cogn Neurosci 13, 892-909.

Garrard, Peter/Lisa M. Maloney/John R. Hodges/Karalyn Patterson (2005b) "The effects of very early Alzheimer's disease on the characteristics of writing by a renowned author." Brain 128, 250-260.

GoodGLASS, Harold/Edith KAPLAN (1983) The assessment of aphasia and related disorders. Philadelphia: Lea and Febiger.

Gorno-Tempini, Maria Luisa/Simona Marina Brambati/Valeria GineX/Jennifer OGAR/Nina F. Dronkers/Alessandra MARCone et al. (2008) "The logopenic/phonological variant of primary progressive aphasia." Neurology 71, 1227-1234.

Gorno-Tempini, Maria Luisa/Nina F. Dronkers/Katherine P. Rankin/Jennifer M. Ogar/La Phengrasamy/Howard J. Rosen et al. (2004) "Cognition and anatomy in three variants of primary progressive aphasia." Ann Neurol 5, 335-346.

Gorno-Tempini, Maria Luisa/Argye E. Hillis/Sandra Weintraub/Andrew KerTesz/Mario MENDEZ/S F CAPPA et al. (2011) "Classification of primary progressive aphasia and its variants." Neurology 76, 1006-1014.

Greene, Jacqueline D./John C. Morris/Jennifer SAndson/Daniel W. Mckeel Jr./Joshua W. MiLler (1990) "Progressive aphasia: a precursor of global dementia?" Neurology 40, 423-429. 
GreENE, John D./John R. HodGes (1996) "Identification of famous faces and famous names in early Alzheimer's disease. Relationship to anterograde episodic and general semantic memory." Brain 119/1, 111-128.

Greene, John D./John R. Hodges/Alan D. BADdeley (1995) "Autobiographical memory and executive function in early dementia of Alzheimer type." Neuropsychologia 33, 1647-1670.

Grossmann, Murray (2010) "Primary progressive aphasia: clinicopathological correlations." Nat Rev Neurol 6, 88-97.

Grundman, Michael/Ronald C. Petersen/Steven H. Ferris/Ronald G. Thomas/Paul S. Aisen/David A. BenNetT et al. (2004) "Mild cognitive impairment can be distinguished from Alzheimer disease and normal aging for clinical trials." Arch Neurol 61, 59-66.

Harasty, Jenny A./Glenda M. Halliday/Jillian J. KRIL/C Code (1999) "Specific temporoparietal gyral atrophy reflects the pattern of language dissolution in Alzheimer's disease." Brain 122/4, 675-686.

Hier, Daniel B./Karen Hagenlocker/Andrea Gellin Shindler (1985) "Language disintegration in dementia: effects of etiology and severity." Brain Lang 25, 117-133.

HiRSCH Katherine W./Andrew W. ElLIS (1994) "Age of acquisition and lexical processing in aphasia: a case study." Cognitive Neuropsychology 11, 435-458.

Hodges, John R./Karalyn PATterson (1995) "Is semantic memory consistently impaired early in the course of Alzheimer's disease? Neuroanatomical and diagnostic implications." Neuropsychologia 33, 441-459.

Hodges, John R./Karalyn PAtTerson (2007) "Semantic dementia: a unique clinicopathological syndrome." Lancet Neurol 6, 1004-1014.

Hodges, John R./Karalyn Patterson/Nadia Graham/Kate Dawson (1996) "Naming and knowing in dementia of Alzheimer's type." Brain Lang 54, 302-235.

HoF, Patrick R./Brent A. Vogt/Constantin Bouras/John H. Morrison (1997) "Atypical form of Alzheimer's disease with prominent posterior cortical atrophy: a review of lesion distribution and circuit disconnection in cortical visual pathways." Vision Res 37, 3609-3625.

Johnson, Julene K./Elizabeth Head/Ronald KIm/Arnold StarR/Carl W. Cotman (1999) "Clinical and pathological evidence for a frontal variant of Alzheimer disease." Arch Neurol 56, 1233-1239.

KemPler, Daniel/Susan CuRTISS/Catherine JACKSON (1987) "Syntactic preservation in Alzheimer's disease." J Speech Hear Res 30, 343-350.

KnibB, Jonathan A./John H. Xuereb/Karalyn Patterson/John R. Hodges (2006) "Clinical and pathological characterization of progressive aphasia." Ann Neurol 59, 156-165.

Kopelman, Michael D. (1985) "Rates of forgetting in Alzheimer-type dementia and Korsakoff's syndrome." Neuropsychologia 23, 623-638.

Lambon RalPh, Matthew A./Karalyn Patterson/Nadia Graham/Kate Dawson/John R. Hodges (2012) "Homogeneity and heterogeneity in mild cognitive impair- 
ment and Alzheimer's disease: a cross-sectional and longitudinal study of 55 cases." Brain 126, 2350-2362.

Leyton, Christian E./Victor L. Villemagne/Sharon Savage/Kerryn E. Pike/Kirrie J. BALlARD/Oliver PIGUET et al. (2012) "Subtypes of progressive aphasia: application of the International Consensus Criteria and validation using beta-amyloid imaging." Brain 134, 3030-3043.

MCCARTHY, Rosaleen/Elizabeth K. WARRINGTON (1985) "Category specificity in an agrammatic patient: the relative impairment of verb retrieval and comprehension." Neuropsychologia 23, 709-727.

MCKenna, Pat/Elizabeth K. WARrington (1980) "Testing for nominal dysphasia." J Neurol Neurosurg Psychiatry 43, 781-788.

Mckhann, Guy/David Drachman/Marshall Folstein/Robert Katzman/Donald Price/Emanuel M. Stadlan (1984) "Clinical diagnosis of Alzheimer's disease: report of the NINCDS-ADRDA Work Group under the auspices of Department of Health and Human Services Task Force on Alzheimer's Disease." Neurology 34, 939-944.

Mesulam, Marsel/Alissa Wicklund/Nancy Johnson/Emily Rogalski/Gabriel C. LEGER/Alfred RADEMAKer et al. (2008) "Alzheimer and frontotemporal pathology in subsets of primary progressive aphasia." Ann Neurol 63, 709-719.

Mesulam, Marsel (1982) "Slowly progressive aphasia without generalized dementia." Ann Neurol 11, 592-598.

Migliaccio, Raffaella/Federica Agosta/Katya Rascovsky/Anna KaRYDAs/Stephen BonaSERA/Gil D. RABINOVICI et al. (2009) "Clinical syndromes associated with posterior atrophy: early age at onset AD spectrum." Neurology 73, 1571-1578.

MirRA, Suzanne S. (1997) "The CERAD neuropathology protocol and consensus recommendations for the postmortem diagnosis of Alzheimer's disease: A commentary." Neurobiology of Aging 18, S91-S94.

Mirra, Suzanne S./Albert Heyan/Daniel W. Mckeel/Mark S. Sumi/B J Crain/L M BrownLEe et al. (1991) "The Consortium to Establish a Registry for AlzheimersDisease (Cerad). 2. Standardization of the Neuropathologic Assessment of Alzheimers-Disease." Neurology 41, 479-486.

Monsch, Andreas U./Mark W. Bodni/Nelson ButTERs/David P. SALmon/Robert KatZMAN/Leon J. THAL (1992) "Comparisons of verbal fluency tasks in the detection of dementia of the Alzheimer type." Arch Neurol 49, 1253-1258.

Nicholas, Marjorie/Loraine K. Obler/Martin L. Albert/Nancy Helm-EstabrooKs (1985) "Empty speech in Alzheimer's disease and fluent aphasia." J Speech Hear Res 28, 405-410.

Perry, Richard J./John R. Hodges (1992) "Attention and executive deficits in Alzheimer's disease. A critical review." Brain 122/3, 383-404.

Perry, Richard J./Peter C. WATson/John R. Hodges (2000) "The nature and staging of attention dysfunction in early (minimal and mild) Alzheimer's disease: relationship to episodic and semantic memory impairment." Neuropsychologia 38, 252-271. 
Petersen, Ronald C./Glenn E. Smith/Stephen C. Waring/Robert J. Ivnik/Eric G. TANGLOS/Emre KoKmen (1999) "Mild cognitive impairment: clinical characterization and outcome." Arch Neurol 56, 303-308.

Petersen, Ronald C./James Stevens/Mary Ganguli/Eric G. Tangalos/Jeffrey L. Cummings/Steven T. Dekosky (2001) "Practice parameter: early detection of dementia: mild cognitive impairment (an evidence-based review). Report of the Quality Standards Subcommittee of the American Academy of Neurology." Neurology 56, 1133-1142.

Price, Bruce H./Hakan Gurvit/Sandra Wientraub/Changiz Geula/Elizabeth Leimkuhler/Marsel Mesulam (1993) "Neuropsychological Patterns and Language Deficits in 20 Consecutive Cases of Autopsy-Confirmed Alzheimers-Disease." Arch. Neurol. 50, 931-937.

PRICE, Cathy J. (2010) "The anatomy of language: a review of 100 fMRI studies published in 2009." Year in Cognitive Neuroscience 2010 1191, 62-88.

Ribeiro, Filipa/Alexandre De Mendonca/M. Guerriro (2006) "Mild cognitive impairment: deficits in cognitive domains other than memory." Dement Geriatr Cogn Disord 21, 284-290.

RohreR, Jonathan S./Gerard R. Ridgway/Sebastian J. CRUTCH/Julia HAILSTONE/Johanna C. Goll/Matthew J. Clakson et al. (2010) "Progressive logopenic/phonological aphasia: erosion of the language network." Neuroimage 49, 984-993.

Rosser, Anne/John R. Hodges (1994) "Initial letter and semantic category fluency in Alzheimer's disease, Huntington's disease, and progressive supranuclear palsy." J Neurol Neurosurg Psychiatry 57, 1389-1394.

SAFFrAn Eleanor M./Rita Sloan BeRNDT/Myrna F. SchwARTZ (1989) "The quantitative analysis of agrammatic production: procedure and data." Brain Lang 37, 440-479.

SAlmon, David P./Wiliam C. Heindel/Kelly L. LANGe (1999) "Differential decline in word generation from phonemic and semantic categories during the course of Alzheimer's disease: implications for the integrity of semantic memory." J Int Neuropsychol Soc 5, 692-703.

SMALl, Brent J./Lars BACKMAN (1998) "Predictors of longitudinal changes in memory, visuospatial, and verbal functioning in very old demented adults." Dement Geriatr Cogn Disord 9, 258-266.

Snowdon, David A./Susan J. KemPer/James A. Mortimer/Lydia H. GreIner/David R. WEKSTEIN/William E. MARKESBERY (1996) "Linguistic ability in early life and cognitive function and Alzheimer's disease in late life. Findings from the Nun Study." Jama 275, 528-532.

Thompson, Sian A./Kim S. Graham/Karalyn Patterson/Barbara J. Sahakian/John R. HoDGES (2002) "Is knowledge of famous people disproportionately impaired in patients with early and questionable Alzheimer's disease?" Neuropsychology $16,344-358$.

Tomoeda, Cheryl K./Kathryn A. BaYLEs (1993) "Longitudinal effects of Alzheimer disease on discourse production." Alzheimer Dis Assoc Disord 7, 223-236. 
Tomoeda, Cheryl K./Kathryn A. Bayles/Michael W. Trosset/Tamiko Azuma/A McGEAGH (1996) "Cross-sectional analysis of Alzheimer disease effects on oral discourse in a picture description task." Alzheimer Disease \& Associated Disorders 10, 204-215.

VAN Velzen, Marjolein/Peter GarRand (2008) "From hindsight to insight: retrospective analysis of language written by a renowned Alzheimer's patient." Interdisciplinary Science Reviews 33, 278-286.

Vuorinen, Elina/Matti Laine/Juha Rinne (2000) "Common pattern of language impairment in vascular dementia and in Alzheimer disease." Alzheimer Dis Assoc Disord 14, 81-86.

Welsh, Kathleen/Nelson Butters/James P. Hughes/Richard C. Mohs/Albert HeYMAN (1991) "Detection of abnormal memory decline in mild cases of Alzheimer's disease using CERAD neuropsychological measures." Arch Neurol 48, 278-281.

Welsk, Kathleen A./Nelson Butters/James P. Hughes/Richard C. Mohs/Albert HeYMAN (1992) "Detection and staging of dementia in Alzheimer's disease. Use of the neuropsychological measures developed for the Consortium to Establish a Registry for Alzheimer's Disease." Arch Neurol 49, 448-452.

Wilson, Stephen M./Maya L. Henry/Max Besbris/Jennifer M. Ogar/Nina F. DronKERS/William JARROLD et al. (2010) "Connected speech production in three variants of primary progressive aphasia." Brain 133, 2069-2088.

Winbald, Bengt/Katie Palmer/Miia KiviPelto/V Jelic/Laura Fratiglioni/Lars-Olof WAHLUND et al. (2004) "Mild cognitive impairment - beyond controversies, towards a consensus: report of the International Working Group on Mild Cognitive Impairment." J Intern Med 256, 240-246.

\section{Abstract \\ SPOKEN DISCOURSE IN ALZHEIMER'S DISEASE: A REVIEW}

In its typical form, Alzheimer's disease (AD) manifests with early impairment in episodic memory. Evidence suggests that language deficits also occur early on in the disease process, and can be detected at the preclinical stage, suggesting that language could constitute an important diagnostic marker for disease. Additionally, a number of variant clinical presentations of $\mathrm{AD}$ are recognised, due to an atypical distribution of pathology at onset, including a minority of patients presenting with a slowly progressive language impairment. We review language performance in typical and atypical presentations of $\mathrm{AD}$, and describe a series of recent, novel findings examining the language phenotype of typical $\mathrm{AD}$.

Keywords: Alzheimer's disease, connected speech, primary progressive aphasia. 
Tipična oblika Alzheimerjeve bolezni se kaže v zgodnji okvari epizodnega spomina. Raziskave kažejo, da se v začetni stopnji bolezenskega procesa pojavljajo tudi jezikovne motnje, ki jih je mogoče zaznati že v predklinični fazi, zaradi česar bi jezik lahko predstavljal pomemben diagnostični marker za to bolezen. Kljub številnim in raznolikim kliničnim oblikam te bolezni, ki so posledica atipičnih patoloških stanj v začetku obolenja, obstaja tudi manjše število bolnikov, pri katerih z napredkom bolezni počasi in postopno slabi tudi njihova jezikovna zmožnost. V prispevku ponujamo pregled raziskanih stopenj jezikovne zmogljivosti v tipičnih in atipičnih oblikah Alzheimerjeve bolezni in predstavimo vrsto nedavnih ugotovitev o spremembah jezikovne rabe pri tipični obliki te bolezni.

Ključne besede: Alzheimerjeva bolezen, povezani govor, primarna progresivna afazija. 